\title{
Diffusion of Palladium on Tantalum Microcrystal
}

\author{
G. Antczak AND R. BŁaszczyszyN* \\ Institute of Experimental Physics, University of Wroctaw \\ pl. M. Borna 9, 50-204 Wrocław, Poland
}

(Received July 5, 2002)

\begin{abstract}
Surface diffusion of palladium, $\Theta=2 \mathrm{ML}$, on a tantalum microcrystal was studied by means of field electron emission microscopy within the temperature range $665-790 \mathrm{~K}$. The observed sharp moving boundary-diffusion proceeds with an activation energy ranging from 1.25 to $1.7 \mathrm{eV} /$ atom, depending on the crystallographic direction.
\end{abstract}

PACS numbers: 79.70.+q, 68.37.Vj, 68.43.Jk, 05.40.Ca

\section{Introduction}

Diffusion is a common phenomenon on solid surfaces. It plays an important role in many surface processes such as formation of submonolayer superlattices, nucleation and crystal growth, faceting, surface reactions, and so on. Studies of surface diffusion provide information concerning variety of interactions in adsorption systems e.g. mutual interaction within the adsorbate or that arising between adsorbent and adsorbate. We have been particularly interested in exploring interaction between Pd layers (adsorbate) and tantalum (substrate). Several methods have been used to investigate physics of surface diffusion [1-6]. Accessible information concerning the adsorption of palladium on tantalum describes mainly electronic properties and atomic structure [7-10]. Investigation of $\mathrm{Pd}$ diffusion on $\mathrm{Ta}$ has been focussed mainly on the mobility of single $\mathrm{Pd}$ atoms and the initial stages of cluster formation on the (110) facet of Ta microcrystal observed by means of field ion microscopy (FIM) [11]. The system $\mathrm{Pd} / \mathrm{Ta}$ was also examined by the combined

*corresponding author; e-mail: rblasz@ifd.uni.wroc.pl 
techniques of FIM and field emission microscopy (FEM) in the aspect of faceting and alloy formation $[12,13]$.

The diffusion of palladium on microcrystal of tungsten was more frequently studied by FIM [14-16] and FEM [17]. FEM is a good method to study the massive transport of adsorbates on a curved surface of a microcrystal, at the apex of the emitter tip, since this allows direct observation of spreading the adspecies. Such measurements provide information concerning the diffusion parameters for various crystallographic directions and regions of the surface. Recently FEM has been used to study the faceting process for adsorption systems such as $\mathrm{Pd} / \mathrm{W}$, Rh/W [18], $\mathrm{Pt} / \mathrm{W}, \mathrm{Pd} / \mathrm{Mo}$ and $\mathrm{Pt} / \mathrm{Ir}[19,12]$ as well as diffusion under conditions when faceting process occurs $[12,20]$. The presented work was initially undertaken to study the faceting process.

\section{Experimental}

The FEM observations were performed under ultrahigh vacuum conditions (total base pressure below $2 \times 10^{-10}$ Torr) in a standard glass microscope tube, attached to a stainless-steel vacuum system. The tube was equipped with a Ta emitter tip assembly, Ti getter, a Bayard-Alpert gauge and a source of palladium. The tantalum emitter tip was electrochemically prepared from wire (of $0.1 \mathrm{~mm}$ in diameter) and spot welded onto a tungsten wire loop. The emitter tip curvature radius was estimated to be about $300 \mathrm{~nm}$. The emitter was thermally cleaned in ultrahigh vacuum by resistive heating a tungsten loop. The temperature of the emitter was determined on the basis of measurements of the resistance of the apex segment of the tungsten wire loop [1,21]. Palladium was deposited on one side of the emitter tip (the angle between the palladium flux and the emitter axis was about 90 degrees) maintained at room temperature from a well-outgassed evaporation source. The source consists of $\mathrm{Pd}$ wire tightly wound around a tungsten wire. Resistive heating the $W$ wire allowed evaporation of palladium.

Diffusion measurements were carried out as follows. The tip was cleaned by increasing its temperature to $2500 \mathrm{~K}$ for a few seconds. Then the temperature was decreased to $760 \mathrm{~K}$ to reduce the roughness of surface [22] (Fig. 1a). A dose of Pd corresponding to an a verage coverage $\Theta=2 \mathrm{ML}$ was deposited onto one side of the clean emitter. A gradient of $\mathrm{Pd}$ population was formed on the surface as a result of shaded deposition, with a sharp boundary between clean and adsorbate-covered regions. The direction of the Pd flux is shown by the arrow in Fig. 1b. The emitter surface and the thermal spreading of the adsorbate was FEM-monitored and the field emission (FE) patterns recorded (Fig. 1c-j), which could be observed directly either on the microscope screen or by using a TV camera and video monitor. After video-tape recording the patterns were computer analysed. The diffusion experiments were carried out at several temperatures in the range $665-790 \mathrm{~K}$. As the spreading proceeded with a sharp diffusion boundary (Fig. 1c-j), the time 

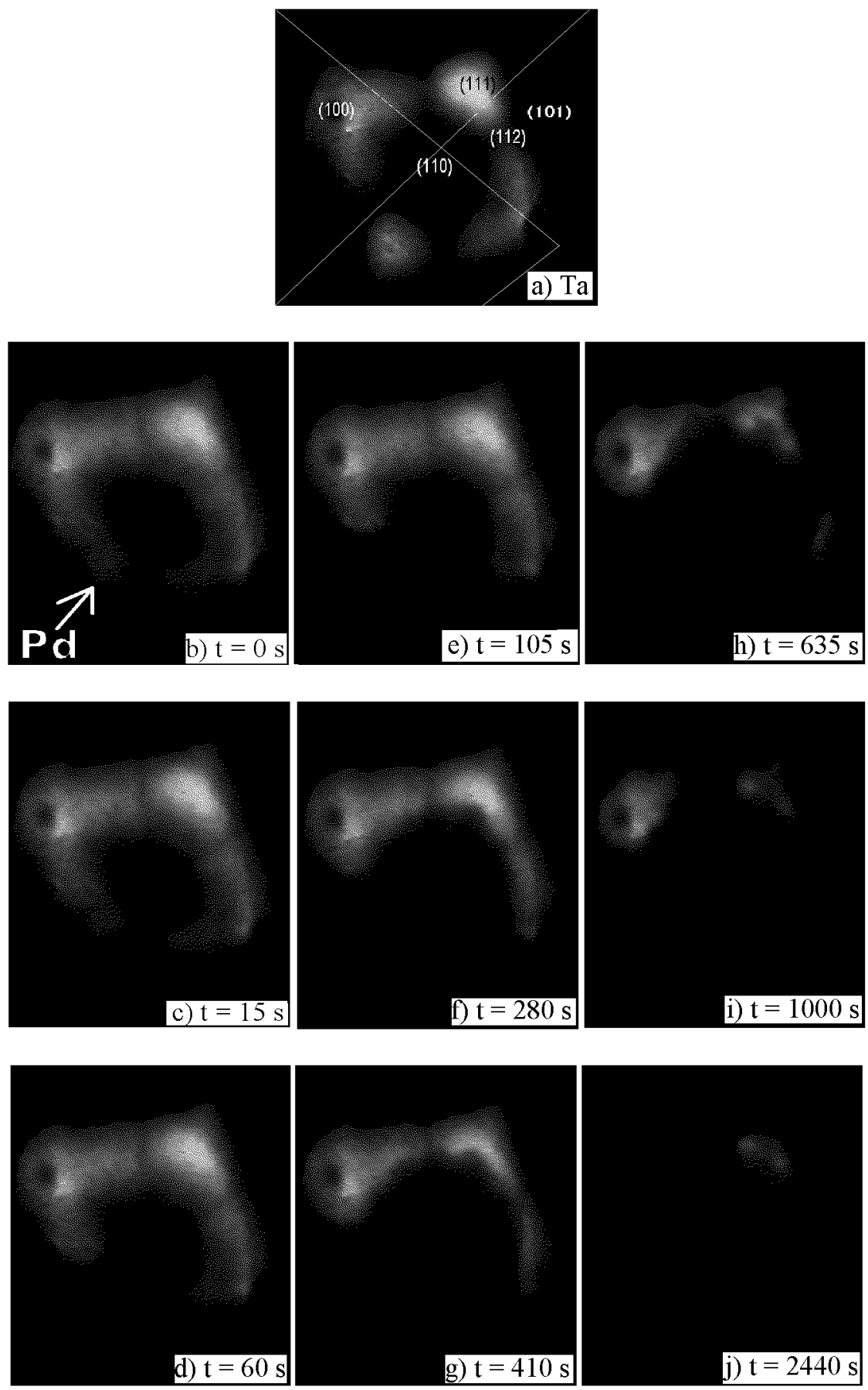

Fig. 1. Typical sequence of field emission patterns of palladium diffusion on tantalum: (a) clean $\mathrm{Ta}$, (b) with initial $\mathrm{Pd}$ deposit $\Theta=2 \mathrm{ML}$ at room temperature, (c)-(j) after heating at $T=665 \mathrm{~K}$; diffusion time $t$ - listed under the patterns. Arrow in (b) shows the direction of $\mathrm{Pd}$ deposition flux. 
dependence for the moving boundary at various temperatures could be plotted (Figs. 2 and 3) and the activation energy for diffusion determined (Figs. 4 and 5). It was assumed that evaporation time of palladium at which the diffusion of $\mathrm{Pd}$ layer started to proceed with a sharp boundary separating clean and covered parts of the substrate surface corresponds to unitary coverage $\Theta=1 \mathrm{ML}$. The diffusion parameters were determined for three crystallographic zone lines of Ta surface: (110)-(111), (110)-(101) and (110)-(100).

\section{Results and discussion}

In contrast to the adsorption of $\mathrm{Pd}$ on $\mathrm{W}$ [18] and Mo [19] microcrystals, the $\mathrm{Pd}$ layer on the Ta emitter tip does not influence the faceting transition of the substrate surface. If any, only a weak rearrangement of the region around the (110) pole could be indicated in the $\mathrm{FE}$ images for $\Theta>1 \mathrm{ML}$ after heating the tip in the temperature range $995-1340 \mathrm{~K}$. Formation of a surface alloy in some crystallographic regions [12] was deduced in an FIM study [13]. Diffusion was monitored in the presence of the electric field (FEM mode) at a strength of $38 \mathrm{MV} / \mathrm{cm}$, but its influence on palladium atoms mobility can be neglected.

Figure 1 shows a typical sequence of FE patterns which reflect stages of the diffusion of a $\mathrm{Pd}$ layer $(\Theta>1 \mathrm{ML})$ over the Ta emitter tip at a temperature of $665 \mathrm{~K}$. Regions of the Ta surface covered by the $\mathrm{Pd}$ layer are displayed in the FE patterns as a dark part of the surface because the $\mathrm{Pd}$ adsorbate reduces electron emission from tantalum. Under this condition diffusion is observable in the FE image owing to the motion of the sharp boundary separating the clean and the adsorbate covered parts of the imaged surface. At higher temperatures the diffusion proceeds similarly to that at $665 \mathrm{~K}$. Plots of the squared distance of the diffusion boundary $X^{2}$ versus time $t$ are shown in Figs. 2 and 3 for three crystallographic zone lines: (110)-(101), (110)-(111) and (110)-(100). The plots are consistent with well-known parabolic relation for diffusion $[2,4]$ :

$$
\left\langle X^{2}\right\rangle \sim D t,
$$

where $D$ is the chemical diffusion coefficient.

Experimental results are usually expressed in terms of the activation barrier $E$ for a diffusing adspecies and the diffusivity $D_{0}$ :

$$
D=D_{0} \exp (-E / k T) \text {. }
$$

The dependence of $\ln \left(\Delta X^{2} / \Delta t\right)$ on reciprocal temperature is shown in Fig. 4. The activation energies of diffusion for the zone lines: (110)-(101), (110)-(111), (110)-(100) amount to $1.25 \mathrm{eV}, 1.45 \mathrm{eV}$, and $1.70 \mathrm{eV}$, respectively. The average activation energy of the diffusion was also determined by measurement of the time $t_{\text {tot }}$ for spreading a $\mathrm{Pd}$ adsorption layer on the whole surface of the emitter tip in the temperature range $665-790 \mathrm{~K}$. In Fig. 5 the dependence of $\ln t_{\text {tot }}$ versus $1 / T$ is presented, and the corresponding average activation energy amounts to $1.45 \mathrm{eV}$. 


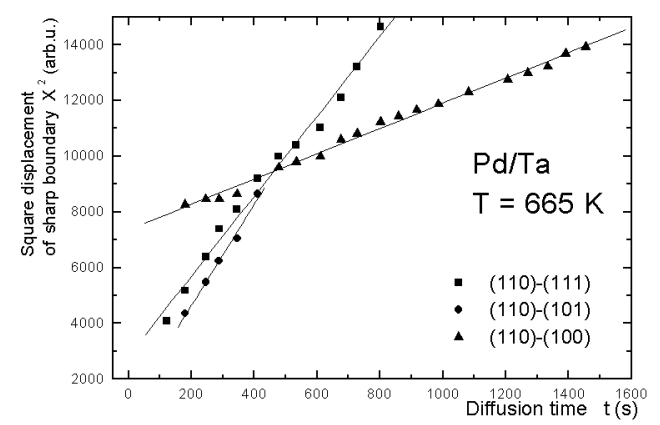

Fig. 2. Squared displacement of sharp diffusion boundary versus diffusion time $t$ at temperature $665 \mathrm{~K}$ along the chosen crystallographic zone lines.
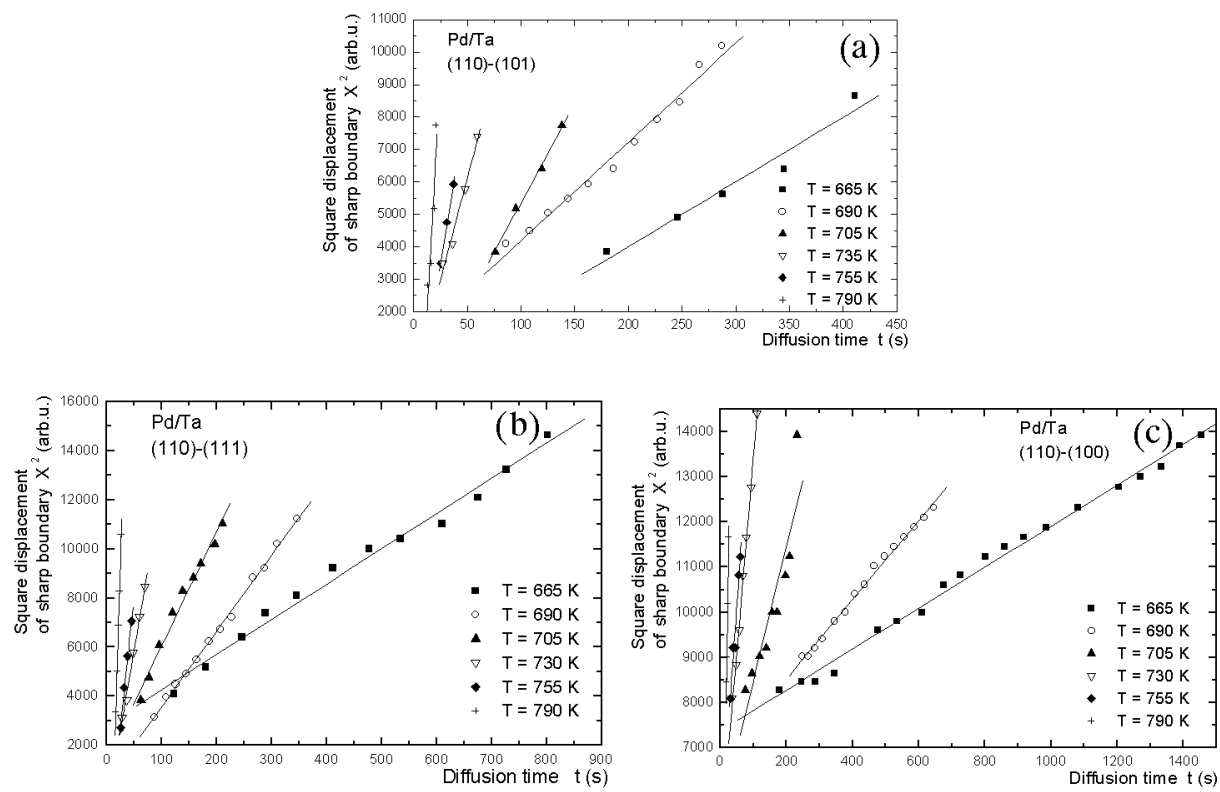

Fig. 3. Time dependence of squared displacement along the zone lines:

(a) (110) $\rightarrow(101)$, (b) (110) $\rightarrow(111)$, (c) (110) $\rightarrow$ (100), at the chosen temperatures.

Although diffusion in the coverage range $\Theta<1 \mathrm{ML}$ was not studied in detail, the spreading of $\mathrm{Pd}$ adatoms was observed to occur without a sharp boundary. The estimated average activation energy of diffusion was around $1.45 \mathrm{eV}$ in this case.

Similarly as in the case of other adsorption systems, two types of diffusion have been observed for palladium on tantalum. One, without a sharp boundary observed for $\mathrm{Pd}$ doses corresponding to an average coverage $\Theta<1 \mathrm{ML}$, and another — with a sharp diffusion boundary for $\mathrm{Pd}$ deposit corresponding to $\Theta \geq 1 \mathrm{ML}$. The second type is well known and proceeds according to the so-called "unrolling carpet" mechanism $[1,3,4]$. (The sharp boundary is observed when the 


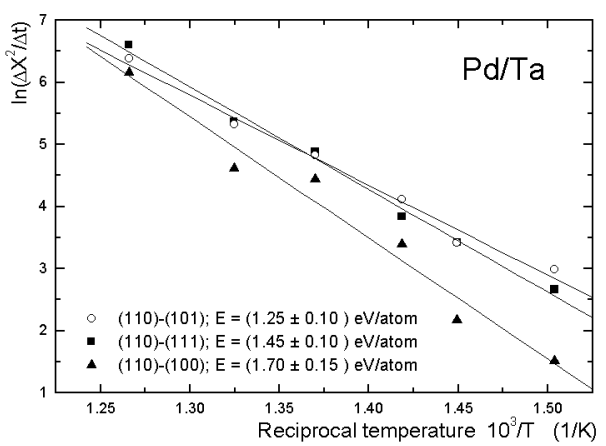

Fig. 4. Arrhenius plots for Pd diffusion of Fig. 3.

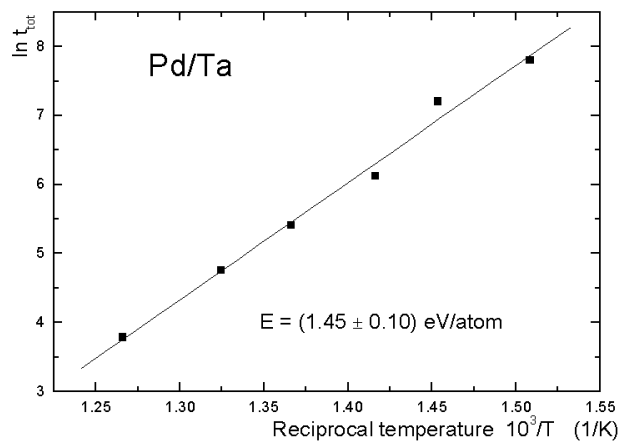

Fig. 5. Arrhenius plot for time of spreading over total surface: Pd on Ta.

jump distance of adatoms does not exceed the resolution of microscope $2 \mathrm{~nm}$.) This mechanism works for the diffusion of atoms in the upper layer to the edge of the covered region, where they are trapped onto the bare surface over which the diffusion barrier is high. The distinction can also arise owing to the effect of interactions between adatoms [1-4].

In Table there are collected values of the activation energy determined by the FIM and FEM methods for the $\mathrm{Pd} / \mathrm{W}$ and Pd/Ta systems. The energy depends on substrate structure and coverage. The diffusion of single atoms has been examined in the past for an atomically smooth and perfect substrate surface obtained by field evaporation $[1,5]$. It is understood that the activation energy in such conditions is much lower than that for multiatomic diffusion on a thermally rough surface by FEM. Although the diffusion of a large dose proceeds mainly over the first Pd monolayer, the substrate structure is not completely shielded by the first layer and a high anisotropy of diffusion is observed. The highest mobility of Pd (the lowest activation energy) occurs along the atomically smoothest zone 
TABLE

Comparison of results.

\begin{tabular}{|c|c|c|c|c|c|c|c|}
\hline System & $\begin{array}{l}\text { Region of } \\
\text { surface }\end{array}$ & $\begin{array}{l}\text { Type of } \\
\text { diffusion }\end{array}$ & Method & $\begin{array}{c}\mathrm{Pd} \\
\text { Cov. } \\
{[\mathrm{ML}]}\end{array}$ & $\begin{array}{c}\text { Temp. } \\
{[\mathrm{K}]}\end{array}$ & $\begin{array}{c}\text { Activation } \\
\text { energy } \\
\text { [eV/atom }]\end{array}$ & Ref. \\
\hline \multirow[t]{7}{*}{$\mathrm{Pd} / \mathrm{W}$} & (110) & single atom & FIM & $\approx 0$ & 190 & 0.51 & [14] \\
\hline & $(110)$ & single atom & FIM & $\approx 0$ & $173-198$ & 0.51 & [16] \\
\hline & (111) & single atom & FIM & $\approx 0$ & $369-381$ & 1.02 & [16] \\
\hline & $(112)$ & single atom & FIM & $\approx 0$ & $100-140$ & 0.31 & [15] \\
\hline & $(112)$ & single atom & FIM & $\approx 0$ & $110-130$ & 0.32 & [16] \\
\hline & $(110)$ & single atom & FIM & $\approx 0$ & $165-210$ & 0.51 & {$[28]$} \\
\hline & $(013)-(015)$ & $\begin{array}{l}\text { moving } \\
\text { sharp } \\
\text { boundary }\end{array}$ & FEM & $<1$ & $470-545$ & 1.04 & [17] \\
\hline \multirow[t]{5}{*}{$\mathrm{Pd} / \mathrm{Ta}$} & $(110)$ & single atom & FIM & $\approx 0$ & $178-197$ & 0.49 & {$[11]$} \\
\hline & $(110)-(101)$ & $\begin{array}{l}\text { moving } \\
\text { sharp } \\
\text { boundary }\end{array}$ & FEM & 2 & $665-790$ & 1.25 & $\begin{array}{l}\text { this } \\
\text { paper }\end{array}$ \\
\hline & $(110)-(111)$ & $\begin{array}{l}\text { moving } \\
\text { sharp } \\
\text { boundary }\end{array}$ & FEM & 2 & $665-790$ & 1.45 & $\begin{array}{l}\text { this } \\
\text { paper }\end{array}$ \\
\hline & $(110)-(100)$ & $\begin{array}{l}\text { moving } \\
\text { sharp } \\
\text { boundary }\end{array}$ & FEM & 2 & $665-790$ & 1.70 & $\begin{array}{l}\text { this } \\
\text { paper }\end{array}$ \\
\hline & average & $\begin{array}{l}\text { moving } \\
\text { sharp } \\
\text { boundary }\end{array}$ & FEM & 2 & $665-790$ & 1.45 & $\begin{array}{l}\text { this } \\
\text { paper }\end{array}$ \\
\hline
\end{tabular}

between $\{110\}-\{101\}$ which consists of close-packed terraces. The highest activation energy along the $\{110\}-\{100\}$ zone reflects the influence of surface roughness on $\mathrm{Pd}$ diffusion. The quasi-circular shape of the diffusion boundary in the $\mathrm{Pd}-\mathrm{Ta}$ system over the region around the (100) pole seen in Fig. 1i suggests that the micromorphology of the tip is constituted by a set of circular and more or less regular steps around the (100) pole. This indicates that in this region diffusion occurs with a low activation energy along the steps (around the (100) pole) between the terraces of the (100) facet (which are atomically smooth). When these sites are filled, the diffusion proceeds across the steps towards the (100) pole. Such a picture of the diffusion over this region is clearly visible for $\mathrm{Pd}$ coverage range $\Theta<1 \mathrm{ML}$ in the form of a bright, shrinking ring similarly to that which has been observed for other systems, e.g.: CO/W [23], Ba/W [24], Ag/W [25], C/W [26], $\mathrm{Si} / \mathrm{Mo}[27]$ and $\mathrm{Pd} / \mathrm{W}[17]$. 
According to previous estimations [12] the diffusion distances amount to $\approx 70 \mathrm{~nm}$ for the three chosen diffusion directions. As the atomic structure of the substrate on which $\mathrm{Pd}$ diffusion has been monitored is different, the determined activation energies $E$ correspond to average values. In this work the diffusion experiments were carried out for $\Theta=2 \mathrm{ML}$, but the results are representative for the coverage range $\Theta>1 \mathrm{ML}$. At multilayer deposit the transport of material proceeds mainly on the top of the first and/or higher layers, thus the interaction between the adsorbent and substrate weakly depends on coverage. In this coverage range an expected attractive interaction in the adsorbate contributes to the increase in activation energy of diffusion. Another question concerns the influence of the adsorbate diffusion on the substrate surface structure. As was mentioned above, some influence in the high temperature range can be expected. However, on the basis of the analysis of FE patterns this effect can be neglected under our experimental conditions.

In order to better understand the process of diffusion of palladium on atomically rough (thermally treated) regions of the Ta microcrystal a mobility of $\mathrm{Pd}$ atoms within coverage range $\Theta<1$ ML should be carefully studied by means of FEM, FIM, and STM.

\section{Conclusion}

Deposition of a large dose of palladium corresponding to a coverage $\Theta=2 \mathrm{ML}$ on one side of the tantalum microcrystal results in surface diffusion which proceeds over rough regions with a sharp anisotropic boundary in the temperature range 665-790 $\mathrm{K}$. The activation energy for the diffusion increases from $1.25 \mathrm{eV}, 1.45 \mathrm{eV}$ to $1.70 \mathrm{eV}$ for the zones (110)-(101), (110)-(111) and (110)-(100), respectively. The average value of the activation energy for diffusion reaches $1.45 \mathrm{eV}$ (as compared to the mean $1.475 \mathrm{eV}$ of the three values). The time of diffusion at a distance of about thousand angstroms at a temperature of $790 \mathrm{~K}$ is of the order of tens of seconds whereas at a temperature of $665 \mathrm{~K}$ it is tens of minutes.

\section{Acknowledgment}

Discussion with Dr. S. Surma is gratefully appreciated. This work was supported by Wrocław University, grant No. 2016/W/IFD/01.

\section{References}

[1] R. Gomer, Field Emission and Field Ionization, Harvard University Press, Cambridge, MA 1961.

[2] D.A. King, J. Vac. Sci. Technol. 17, 241 (1980). 
[3] A.G. Naumovets, Yu.S. Vedula, Surf. Sci. Rep. 4, 365 (1985).

[4] R. Gomer, Rep. Prog. Phys. 59, 917 (1990).

[5] G.L. Kellogg, Surf. Sci. Rep. 21, 1 (1994).

[6] J.V. Barth, Surf. Sci. Rep. 40, 75 (2000).

[7] J. Kołaczkiewicz, E. Bauer, Surf. Sci. 256, 87 (1991).

[8] I. Ubogyi, J. Kołaczkiewicz, Vacuum 49, 145 (1998).

[9] Š. Pick, P. Mikišik, J. Phys., Condens. Matter 5, 6581 (1993).

[10] M.W. Ruckman, M. Strongin, Phys. Rev. B 35, 487 (1987).

[11] P.R. Schwoebel, G.L. Kellogg, Phys. Rev. B 38, 5326 (1988).

[12] G. Antczak, Ph.D. Thesis, University of Wrocław, Wrocław 2002.

[13] A. Szczepkowicz, Ph.D. Thesis, University of Wrocław, Wrocław 2001.

[14] D.W. Bassett, Thin Solid Films 48, 237 (1978).

[15] D.C. Senft, G. Ehrlich, Phys. Rev. Lett. 74, 294 (1995).

[16] Tsu-Yi Fu, Lung-Chieh Cheng, Yi-Ju Hwang, Tien T. Tsong, Surf. Sci, in press.

[17] H. Roux, A. Piquet, R. Uzan, M. Drechsler, Surf. Sci. 141, 301 (1984).

[18] K. Pelhos, T.E. Madey, Surf. Sci. 426, 61 (1999).

[19] G. Antczak, T.E. Madey, M. Błaszczyszyn, R. Błaszczyszyn, Vacuum 63, 43 (2001)

[20] G. Antczak, T.E. Madey, R. Błaszczyszyn, in preparation.

[21] C.J. Workowski, J. Phys. E 10, 538 (1997).

[22] E.W. Müller, J. Appl. Phys. 26, 732 (1955).

[23] T. Engel, R. Gomer, J. Chem. Phys. 50, 2428 (1969).

[24] M. Drechsler, Z. Electrochem. 58, 327, 340 (1954).

[25] J.P. Jones, Surf. Sci. 32, 29 (1972).

[26] T. Radoń, Acta Phys. Pol. A 50, 3 (1973).

[27] G. Venkatachalam, M.K. Sinha, Surf. Sci. 44, 157 (1974).

[28] S.M. Oh, S.J. Koh, K. Kyuno, G. Ehrlich, Phys. Rev. Lett. 88, 236102 (2002). 